\title{
Economic resilience and hybridization of development - A case of the Central European Regions
}

Adam Drobniak This paper addresses the initial diagnosis and

University of Economics in

Katowice, Poland

Department of Strategic and

Regional Science

E-mail:

adam.drobniak@ue.katowice.pl

Keywords:

economic resilience, regions, regional resilience,

hybridization,

Central Europe evaluation of economic resilience among European Union (EU) countries, focusing on the Central European regions. Empirical analyses show variety considerable differences in the economic positions of territorial units, which calls for the concept of hybridization, enabling the interpretation of different patterns of development in a territorial dimension. The main aim of this paper is to capture the phenomenon of hybridization development by demonstrating the high economic differentiation that determines the difference in resilience across the EU.

\section{Introduction}

This article introduces the study of economic resilience and analyses its effects in EU countries, focusing on the regions of Central Europe. Discovering and building territorial adaptability accounts for global socio-economic trends and leads to the combination of existing businesses with new technologies. Consequently, unsustainable growth dynamics are impacted by external distortions. In the case of countries and regions, this means that parallel occurrences of the growth and stagnation stages occur, resulting in multiple trajectories of change.

The diversity and multiple trajectories of economic change can be interpreted in terms of hybridization of development, which in recent years has often been referenced as a concept that explains the unconnected, and highly diverse development trends (Patkar-Keskar 2014). Hybridization is perceived as an intrinsic component of the modern growth dynamics that determine the level of resilience spanning the spatial organisation of socio-economic systems. The main reason for hybridization in the business and territorial sphere is the need for rapid transformation of production in a cosmopolitan, consumer-oriented, and globalised world (i.e. the searching and building of adaptability as a main driving force of resilience).

Is hybridization of development explained by the randomness of economic processes or can it be regarded as a new pattern of development? Contemporary developmental effects, including often unexpected industry and technology links, may be interpreted as random without a detailed analysis. Nevertheless, more detailed iden-

Regional Statistics, Vol. 7. No.1. 2017: 043-062; DOI: 10.15196/RS07103 
tification of such processes reveals a hybrid of solutions and effects. In general, accounting for the above considerations, one can hypothesize that building the adaptability of economic systems (i.e. their resilience) in the globalised and digital world results in new patterns of development that often take the form of hybrids.

Bearing in mind the above-mentioned considerations, this paper aims to capture the phenomenon of hybridization development by demonstrating the high economic differentiation that determines the difference in economic resilience across the EU, with particular emphasis on Central Europe. The article covers issues related to a theoretical introduction to the economic resilience of regions, initial empirical research on economic resilience of the EU countries and regions of Central Europe, and formulation of conclusions linking the issue of resilience with the hybridization category. In the methodological section, attempts have been made to carry out quantitative comparative analyses of territorial units (the EU countries [ $\mathrm{n}=28]$ and the Central European regions at NUTS 2 level [ $\mathrm{n}=53]$ ) based on indicators (both classical and the author's) of GDP size and dynamics. The lifespan of conducted analysis covers the period of 2000-2014.

\section{Regions' economic resilience}

The regional resilience concept has increasingly become a supporting concept for the diagnosis of regions and cities and development of programming in the last decade. Its roots go back to the debate about sustainable development, which links resilience with climate change and exogenous shocks (Simme-Martin 2010). The resilience concept is triggered by both general notions (i.e. adaptive capacity, determined by learning skills, entrepreneurship, innovations, and self-organisation (Hudson 2010)) and the vulnerability of a system to external shocks such as financial crises, energy crises, and floods (Bosher-Coaffee 2008).

In terms of adaptive capacity, the regional resilience concept may lead to a few essential lines of research. The first refers to the identification of attributes, factors, and indicators for measuring resilience, which permits deep diagnosis of regional and urban systems (descriptive dimension). The second is focused on the planning and implementation of measures for a regional system's best possible adaptation to and preparation for exogenous disruptions (normative dimension). The third is concentrated on comparative studies of regions and cities' paths of development, disruptions, and methods of recovery (evolution dimension). All these lines of research are to some extent the consequence of studies from post-positivistic epistemology (Walker et al. 2006) and apply systemic thinking to understand the subject of study as a complex, multidimensional, open regional or urban system.

The list of definitions of resilience or regional and urban resilience emphasise different aspects of the phenomenon. One of the definitions perceives resilience as a reaction to specific extraordinary events (Simme-Martin 2010), while another

Regional Statistics, Vol. 7. No.1. 2017: 043-062; DOI: 10.15196/RS07103 
highlights resilience as the stability of a system against interference (Welter-Enderlin 2006, Lang 2011). There are also approaches that draw attention to system capacity, which allows a system to avoid and manage natural and human-induced hazards (Bosher-Coafee 2008). Generally, in regional science it is assumed that regions and cities are complex adaptive systems of people, economy, and environment, selforganised with a few critical processes creating and maintaining this selforganisation (Hooling 2001) and determining their resilience capacity. This means that regional or urban resilience should be defined in terms of a flexible society and economy that can anticipate, prepare for, respond to, and recover from a disturbance (Bernett 2001, Foster 2007).

Previous and current studies of the resilience concept conclude that a resilient system, such as a region or city, tolerates exogenous disruptions through certain general attributes that determine the disruptions' impact, reducing 'damage and disruption, and allowing the system to respond, recover, and adapt quickly to such disturbances' (Wardekker et al. 2010).

These kinds of attributes, which build and enhance regional or urban resilience, comprise adaptability, diversity, efficiency, redundancy, collaboration, and interdependence (Godschalk 2003, Klein 2003, Walker-Salt 2006, Taşan-Kok-Stead-Lu 2013). According to this approach, a resilient region is one that has the appropriate combination of these attributes to cope with exogenous disturbances within the process of the region's transition. In the context of the diagnosis of the resilience phenomenon, these kinds of attributes, measured for a particular region or regions, seem to be very interesting in examining the assessment of resilience (Drobniak 2014), because they enable a holistic view of a region as a complex system and a decomposition of the region system into traits that may be further decomposed into resilience and vulnerability factors and indicators (Berkas et al. 2003). In an overall assessment of regional resilience, these attributes can be identified within basic regional structures like economic-technological, socio-cultural, environmental-spatial, and institutional-political ones (Drobniak 2014). In this way, economic regional resilience refers to a region's structures that are responsible for creating, manufacturing, distributing, and selling products and services in internal and external markets. Social resilience focuses on a region's demographic and community behaviour patterns, beliefs, and attitudes.

Several conclusions arising from contemporary resilience studies can be applied to the diagnosis and evaluation of regional or urban resilience. For example, Desmet and Rossi-Hansberg (2009) argue that regional economies may be restored after experiencing exogenous disruptions if their firms can introduce new goods or services for export or use new technologies to produce such goods or services relatively quickly. According to Gerst (2009), the path of recovery varied considerably among regions impacted by exogenous disruptions. Some (i.e. those whose economies are based on services) perform better than those dealing predominately with

Regional Statistics, Vol. 7. No.1. 2017: 043-062; DOI: 10.15196/RS07103 
manufacture. Hill's research on resilience in metropolitan areas of the U.S. (Hill et al. 2010) notes that a metropolitan area's industry structure affects the likelihood that the region will experience a downturn, assuming that old economic structures imply a higher probability of downturn. A cyclical demand for durable goods, which are produced by a more traditional economic structure, makes employment in such sectors more vulnerable to exogenous shocks, such as economic crises.

According to Feyrer (2007), the employment and population of regions dominated by traditional industries, like the automotive and steel industry, stopped growing for about two decades after the regions experienced an economic crisis. On the other hand, the economic resilience of metropolitan cores located near traditional industry areas in fact positively impacted (in terms of resilience) by metropolital cores. Contrastingly, Briguglio (2006) stressed that concentration of a nation's export in a few industries inhibits regional economic resilience. Additionally, factors like human capital and the educational attainment or skills of a region's workforce (Gleasier-Saiz 2004), region-specific institutions, behavioural norms, knowledge, and technology (Nunn 2009) comprise the major driving forces of resilience and have a long-lasting impact on regional resilience.

In this paper, the analysis of resilience of the Central European regions was restricted in scope to its diagnosis and evaluation in reference to economic aspects. Economic resilience is about coping with slow and/or radical change in a region's economy that results from the interactions of endogenous and exogenous conditions (Eraydin-Taşan-Kok 2013). Regional economic resilience refers to the ability of the economy to recover or adjust to exogenous economic shocks and benefit from positive changes. Thus, there are two basic types of a region's economy's reaction to changes: 'recover quickly from a shock' and 'withstand the effects of shock' (Briguglio et al. 2008).

In analysing field studies and referring to the attributes of a region's resilience, mentioned above, a set of specific factors determining regional economic resilience can be defined (see Table).

According to Cooke (2008), one strategy for a region's adaptation to changes is to develop a system of innovation to create or attract new technologies and new products that can quickly find demand in the external market. This means that a region is resilient if after an economic shock it can develop new value chains corresponding to the national and/or external global market. The potential to attract new technologies is affected by many other factors determining the competitive advantages of a particular location, place image, capacity of local firms to cooperate, quality of labour force, and tax incentives. Thus, economic resilience applies to regions based on their local knowledge assets and infrastructure, which can 'produce' new knowledge, allowing for further successful diversified specialisation of the economic base. In this process, a region's ability to convert existing industries, their tradition, labour skills, and accumulated knowledge, and then mix them with a creative capacity to cause new sectors to emerge plays a critical role.

Regional Statistics, Vol. 7. No.1. 2017: 043-062; DOI: 10.15196/RS07103 


\begin{tabular}{|c|c|}
\hline \multicolumn{2}{|r|}{ Factors enhancing a region's economic resilience } \\
\hline Resilience attributes & Factors of economic resilience (examples) \\
\hline Adaptability & $\begin{array}{l}\text { - high entrepreneurship spirit } \\
\text { - high capacity for innovating } \\
\text { - significant local knowledge assets (i.e. knowledge base, research infrastructure, } \\
\text { and transmission of knowledge) }\end{array}$ \\
\hline Connectivity & $\begin{array}{l}\text { - networks of economic actors (i.e. clustering in production and distribution } \\
\text { chains) } \\
\text { - cross-sectoral knowledge linkages (i.e. platforms in innovation, commercialisa- } \\
\text { tion chain, and spill-over effects) }\end{array}$ \\
\hline Diversity & - diverse specialisation of industries (i.e. industrial mix) \\
\hline Efficiency & $\begin{array}{l}\text { - over-local competitiveness } \\
\text { - high value added in production chains (i.e. profitable value chains, as in } \\
\text { knowledge intense industries) } \\
\text { - recovery quickness }\end{array}$ \\
\hline Redundancy & $\begin{array}{l}\text { - effective and durable energy sources } \\
\text { - redundant ICT application }\end{array}$ \\
\hline Interdependency & $\begin{array}{l}\text { - economic cooperation patterns } \\
\text { - complementarities of local industries (i.e. external and internal, including ag- } \\
\text { glomeration effects) }\end{array}$ \\
\hline
\end{tabular}

Summing up, a region's economic resilience can be defined as the ability to successfully foresee technology trends and produce an efficient and effective capitalization of these changes via the regional economic base of national and global markets (Drobniak 2014). The strength of human capital creativity and entrepreneurial skills in a region, a region's networking patterns among business environment players, and the supporting infrastructure impact the level of economic resilience to a vast extent. Thus, the diagnosis and evaluation of a region's economic resilience can be structured in many different ways. In qualitative dimensions, accounting for the attributes and factors of economic resilience mentioned above, this phenomenon may be analysed using tools like focus group interviews (FGI) and individual indepth interviews (IDI) with business players in a particular region, focusing on networking patterns among small businesses and large companies, creation of production and value chains in the national and global environment, the quality of the business supporting infrastructure, and factors determining individuals' economic activity. In the quantitative approach, regional economic resilience can be measured by long run indicators of GDP level, employment level, value of goods sold in the service and manufacturing sectors, volume of investment, number of enterprises run by individuals, number of patents, level of employment in R\&D units, number of spill-overs operating in technological parks, value of export, and inflow of taxes from companies (Drobniak 2012, Eraydin 2016, Hill et al. 2010).

Regional Statistics, Vol. 7. No.1. 2017: 043-062; DOI: 10.15196/RS07103 


\section{Data and method}

Comparatively analysing regional economic resilience has limitations, like any other study. In the current study, the diversity within Central Europe, its area of focus, poses a limitation. The first limitation is connected with the variety of such regions. The diversity manifests in the different potentials of the regions' area, population, economy, history, and institutions. The Central European regions form a wide mosaic of socio-economic structures. Simultaneously, though, they have a common legacy connected with post-socialism experiences, and all of them joined the EU in the first decade or at the beginning of the second decade of twenty-first century. Thus, it is cognitively interesting to analyse their paths of economic development in the face of global changes, which have taken place in recent years.

Another obstacle is the limited possibility of gathering both qualitative and quantitative information about the level of a region's economic resilience. Accounting for the scope of this paper and its aim, the analysis was restricted to the quantitative dimension. This assumption narrows the scope of the study but allows for the preliminary comparative study of such regions in the dimension of economic resilience.

Finally, the analysis of resilience for the Central European regions, in the quantitative dimension, was conducted with the following assumptions:

- All data used in calculations are from the EUROSTAT database. It was assumed that Central European regions (CER) include eight countries of Central Europe (i.e. Bulgaria, the Czech Republic, Croatia, Hungary, Poland, Romania, Slovenia, and Slovakia). Thus, the first selection criterion involves the central location of the mentioned countries and the European regions into which they fall. All these countries, along with their regions, have a strong post-socialism legacy (the second selection criterion), although this legacy is distinguished in various ways. The selected countries also belong to the EU structures (the third selection criterion), which allows them to benefit from EU supporting schemes like structural funds. Finally, this group of countries includes 53 NUTS 2 regions, for which all resilience indicators were calculated.

- Due to the need to capture a broader overall context of interpretation for the resilience phenomenon, resilience indicators were calculated in the following spatial dimensions: (a) for all the EU countries $[\mathrm{n}=28]$ with some focus on the Central European countries $(n=8)$ and $(b)$ for the entire Central European region $[\mathrm{n}=53]$.

- The analysis period covers the years 2000-2014 and includes the EU preaccession period and the full EU accession time for the Central European countries. This lifespan includes both positive and negative economic phenomena, like the economic slowdown in 2001-2003 (e.g. in Poland), followed by the favourable economic cycle (2004-2008), the global financial crisis (2008-2010), and the recovery period after this shock (2011-2014). These ex-

Regional Statistics, Vol. 7. No.1. 2017: 043-062; DOI: 10.15196/RS07103 
ternal changes and disruptions make the surveyed period cognitively interesting for resilience investigations.

- Some of the resilience indicators' calculations were based on Hill's research methodology (Eraydin 2016, Hill et al. 2010) (i.e. dynamic indexes with a fixed baseline were calculated and analysed). However, due to the weaknesses of the fixed baseline indicators used by Hill (i.e. their high dependence on the baseline value), the author's indicators of resilience based on simple descriptive statistics measures were proposed in addition to their combination in the form of portfolios. Resilience investigations for the Central European regions were limited to economic dimensions.

- Economic resilience was measured for all the EU countries and for all the 53 Central European regions with the efficiency attribute of resilience using the following indicators:

- Economic portfolio no. 1 (named the scale and dynamics of GDP) consists of two indicators: the average value of GDP in the period 2000-2014 (x-variable) and the average dynamics of GDP in the period 2000-2014 (y-variable). Both indicators were standardised to a maximum, with a maximum value of 1.0. Economic portfolio no. 1 was prepared to capture the overall changes in development trends and their scale in the EU countries and Central European regions. These assumptions refer to Figure 1 and Figure 5;

- Economic portfolio no. 2 (named the changeability and force of changes of GDP) consists of two indicators: the coefficient of GDP variation measured for the period 2000-2014 (x-variable) and the force of GDP change in the period 2000-2014 (y-variable). The first indicator refers to the changeability of GDP level, which shows its dynamics instability (or stability). The second indicator is statistically defined as the GDP dynamics index in 2014 (where $2000=100$ ) multiplied by an average value of GDP in the period 2000-2014. This second indicator compensates for the weaknesses of a fixed base index (i.e. excessive dependence on the baseline value), and it reveals the overall ('value of GDP' $x$ 'its changes') impact of GDP changes (i.e. the scale of an economy along with its changes). In its construction, the force of GDP change index is similar to the momentum used in physics. Both indexes are standardised to a maximum, with a maximum value of 1.0. Economic portfolio no. 2 was prepared to capture the overall changeability of GDP (stability or instability of GDP) and the force of GDP changes. These assumptions refer to Figure 2 and Figure 6;

- Dynamics of GDP for the period 2000-2014, where GDP was reported at current market prices in millions of euros, and the dynamics indicators assumed the base year to be $2000(2000=100)$. Dynamics of GDP indicators were calculated for all 'old' EU countries (Figure 3) and for eight Central

Regional Statistics, Vol. 7. No.1. 2017: 043-062; DOI: 10.15196/RS07103 
European countries (Figure 4). In the case of the Central European regions, special attention was paid to the economic resilience measured for the ten best and the ten worst regions (the best and the worst-case method, as shown in Figure 7 and Figure 8). Consequently, this approach allowed us to capture the range of differences in the pace of development of Central European regions.

\section{Findings}

Both in absolute and in standardised terms, there are four 'big' economies among the EU countries. The biggest is Germany (DE) followed by the United Kingdom (UK), France (FR), and Italy (IT) (see Figure 1). However, the economies of these countries are characterised by low growth dynamics. During the period 2000-2014, there are also six 'development leaders' that recorded very high economic development dynamics. The highest development refers to Romania (RO) followed by Slovakia (SK), Estonia (EE), Bulgaria (BG), Latvia (LT), and Lithuania (LV). Their economies, however, measured by the average value of GDP, are relatively small in comparison to the EU 'big' economies.

In addition to these strongly polarised groups of countries, there are a few others. The first consists of the Czech Republic (CZ), Hungary (HU), Luxemburg (LU), Malta (MT), Croatia (HR), Slovenia (SI), and Cyprus (CY), whose economies developed with a good GDP growth pace in the period 2000-2014, but whose overall scale of economies is relatively small. The second includes medium-sized economies with relatively good GDP growth dynamics like Poland (PL), Ireland (IE), Spain (ES), the Netherlands (NL), Austria (AT), Belgium (BE), Finland (FI), Denmark (DE), and Sweden (SE). There is also a third group, including countries like Portugal (PT) and Greece (EL), in which both the size of the economy and the development pace in the period of 2000-2014 are relatively small in relation to other EU countries (see Figure 1).

This kind of huge diversity of economic development is also seen in economic portfolio no. 2, which deals with the stability and instability of GDP growth dynamics and the scale of GDP changes in EU countries in the period 2000-2014 (see Figure 2). Similarly, as in portfolio no. 1, there is a group of four countries (Germany - DE, the United Kingdom - UK, France - FR, and Italy - IT) in which the force of GDP changes (measured by economies volumes and their growth dynamics) dominates that of almost all EU countries. In this case, the force of GDP change is predominately determined by GDP volume, and the changes are relatively very small, as confirmed by the low coefficient of GDP variation. The low coefficient of GDP variation also confirms the small but stable growth dynamics of the mentioned countries, and thus their relatively good resilience.

Regional Statistics, Vol. 7. No.1. 2017: 043-062; DOI: 10.15196/RS07103 
Figure 1

Economic portfolio no. 1: scale and dynamics of GDP in EU countries (2000-2014) - standardised values

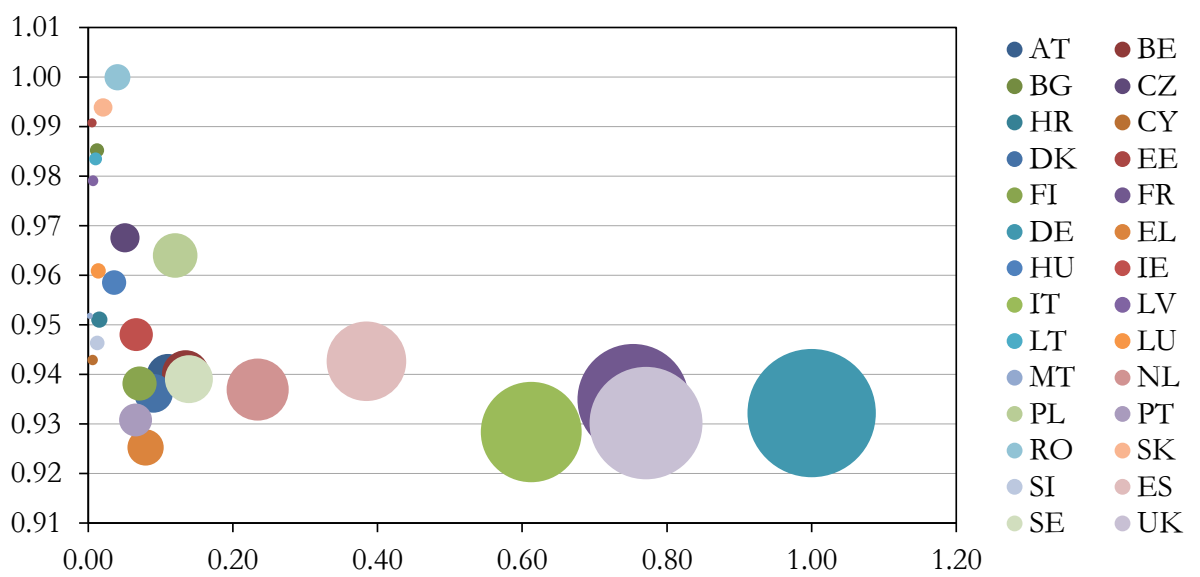

Source: calculation based on EUROSTAT.

Abbreviations: (AT) Austria, (BE) Belgium, (BG) Bulgaria, (CY) Cyprus, (CZ) the Czech Republic, (DE) Germany, (DK) Denmark, (EE) Estonia, (EL) Greece, (ES) Spain, (FI) Finland, (FR) France, (HR) Croatia, (HU) Hungary, (IE) Ireland, (IT) Italy, (LT) Latvia, (LU) Luxemburg, (LV) Lithuania, (MT) Malta, (NL) the Netherlands, (PL) Poland, (PT) Portugal, (RO) Romania, (SE) Sweden, (SI) Slovenia, (SK) Slovakia, and (UK) the United Kingdom.

Figure 2

Economic portfolio no. 2: changeability and force of changes of GDP in EU countries (2000-2014) - standardised values

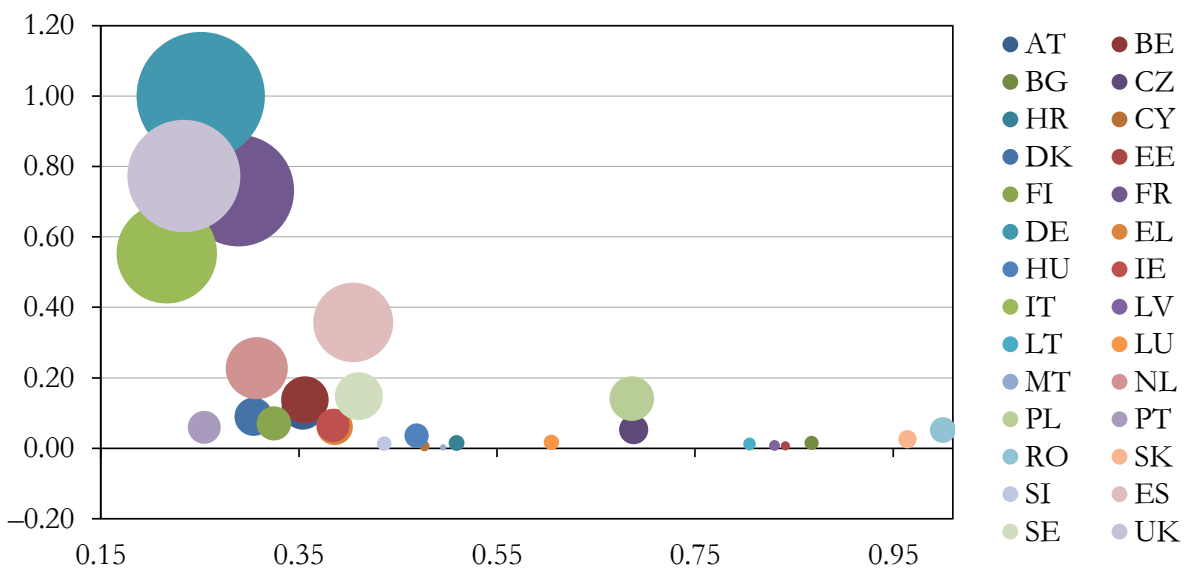

Source: calculation based on EUROSTAT.

Abbreviations: (AT) Austria, (BE) Belgium, (BG) Bulgaria, (CY) Cyprus, (CZ) the Czech Republic, (DE) Germany, (DK) Denmark, (EE) Estonia, (EL) Greece, (ES) Spain, (FI) Finland, (FR) France, (HR) Croatia, (HU) Hungary, (IE) Ireland, (IT) Italy, (LT) Latvia, (LU) Luxemburg, (LV) Lithuania, (MT) Malta, (NL) the Netherlands, (PL) Poland, (PT) Portugal, (RO) Romania, (SE) Sweden, (SI) Slovenia, (SK) Slovakia, and (UK) the United Kingdom.

Regional Statistics, Vol. 7. No.1. 2017: 043-062; DOI: 10.15196/RS07103 
Completely different position is reported for the relatively small economies of Romania, Slovakia, Bulgaria, Estonia, Latvia and Lithuania. In turn, those countries are characterised by very high level of GDP dynamics changeability (i.e. high level of coefficient of GDP variation), what proves their high GDP growth dynamics, but also 'a rollercoaster' type of resilience (Drobniak, 2014).

Apart from these two strongly polarised groups of countries, one can distinguish a few others. The first group refers to countries with a medium-sized force of GDP changes and relatively low (but stable) changeability of GDP growth. This group includes the Netherlands (NL), Spain (ES), Belgium (BE), Sweden (SE), and Poland (PL). Poland, however, differs significantly from this group, because of its high level of GDP changeability. The second group consists of countries with a relatively small force of GDP changes and relatively small changeability of GDP growth. This group includes the rest of the EU countries. One exception is the Czech Republic, which, like Poland, represents a relatively higher level of GDP changeability (see Figure 2).

Now, a few words about 'standard' indicators of GDP dynamics for period the 2000-2014. In the case of 'old' EU countries, the value of GDP dynamics indicators varies among countries. The highest growth is reported for Luxemburg (LU), and the lowest for Greece (EL). Almost all 'old' EU countries faced the global financial crisis in 2008. Some of them were hit by the financial crisis very severely, like Cyprus (CY), Spain (ES), Greece (EL), Portugal (PT), and Italy (IT). This confirms their low economic resilience. For other countries, the financial shock of 2008 hit their economies in a gentler way. Countries like Germany (DE), France (FR), Denmark (DE), Ireland (IE), Belgium (BE), Sweden (SE), Austria (AT), and the Netherlands (NL) bounced back to their previous path of development in a year or in a few years. This also confirms their relatively good economic resilience attributes (see Figure 3).

A very interesting case is presented by the United Kingdom (UK) economy. Its GDP growth dynamics collapsed most severely among the 'old' EU countries after 2007, and it recovered only in 2014. This also confirms the UK economic resilience, but the recovery process has taken over seven years.

What was the economic performance of the Central European countries in the period of 2000-2014? All Central European countries recorded very high GDP growth dynamics (see Figure 4), which were much higher than those registered for the 'old' EU countries. The highest (i.e. almost $370 \%$ of the GDP value of the year 2000) was reported for Romania (RO), followed by Slovakia (SK) and Bulgaria (BG). These countries increased their economies more than three times (Bulgaria and Slovakia) or even close to four times (Romania). The economies which doubled during 2000-2014 belong to Poland (PL), the Czech Republic (CZ), and Hungary (HU). Slightly lower GDP growth was registered for Croatia (HR) and Slovenia (SI).

Regional Statistics, Vol. 7. No.1. 2017: 043-062; DOI: 10.15196/RS07103 
Dynamics of GDP in 'old' EU countries (2000-2014, 2000=100)

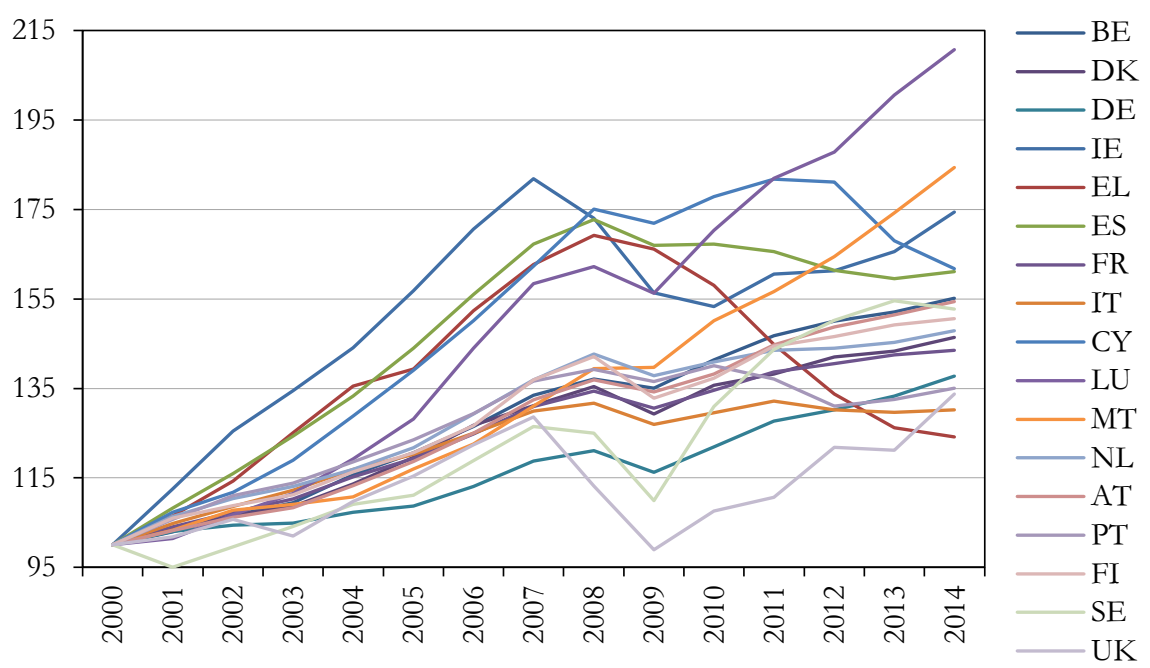

Source: calculation based on EUROSTAT.

Abbreviations: (AT) Austria, (BE) Belgium, (CY) Cyprus, (DE) Germany, (DK) Denmark, (EL) Greece, (ES) Spain, (FI) Finland, (FR) France, (IE) Ireland, (IT) Italy, (LU) Luxemburg, (MT) Malta, (NL) the Netherlands, (PT) Portugal, (SE) Sweden, and (UK) the United Kingdom.

Figure 4

Dynamics of GDP in Central European countries $(2000-2014,2000=100)$

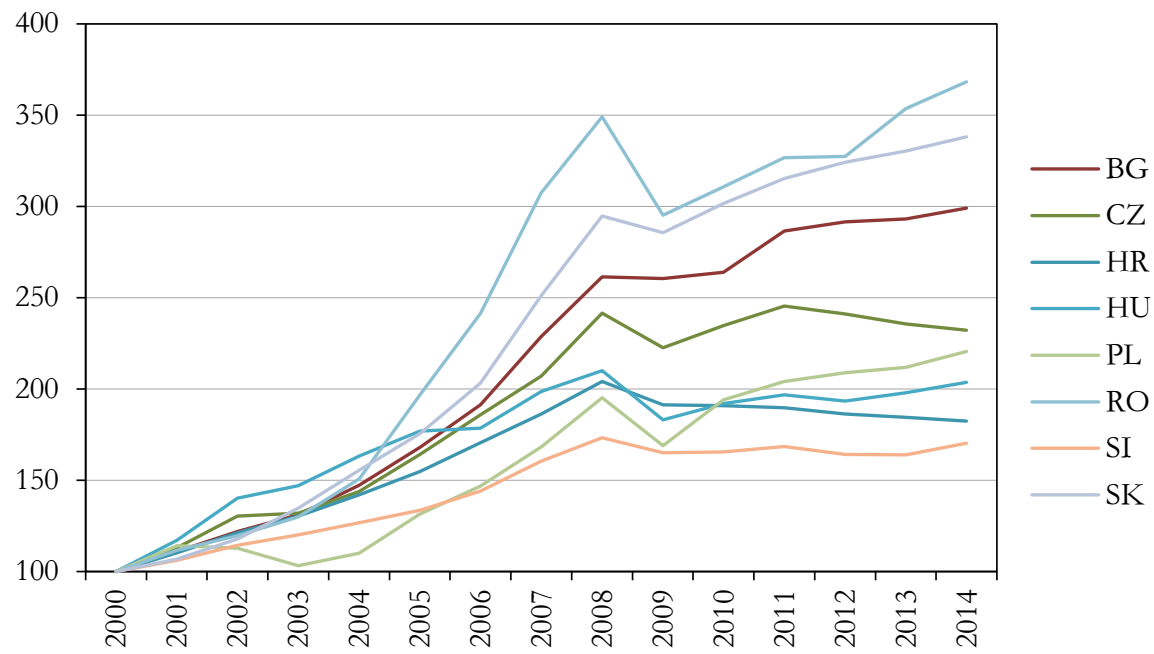

Source: calculation based on EUROSTAT.

Abbreviations: (BG) Bulgaria, (CZ) the Czech Republic, (HR) Croatia, (HU) Hungary, (PL) Poland, (RO) Romania, (SI) Slovenia, and (SK) Slovakia.

Regional Statistics, Vol. 7. No.1. 2017: 043-062; DOI: 10.15196/RS07103 
Like the countries of the 'old' EU, all Central European countries were hit by the global financial crisis in 2008. The crisis has reduced GDP growth dynamics most in Romania (RO). The economic recovery process took five years in this country. In two other countries (i.e. Slovakia (SK) and Poland (PL)) the economic recovery took only two years. In one of the countries, Bulgaria (BG), the GDP dynamics remained 'unshakeable' with respect to the force of the financial crisis. Thus, the economies of Romania, Slovakia, and Poland can be perceived as resilient, and the economy of Bulgaria as even shock-resistant.

There are other types of Central European countries whose paths of economic growth differ from the patterns described above. The first case is that of Slovenia (SI), whose economic growth after 2008 stopped and which has entered a horizontal trend. The second is that of Croatia (HR), whose economic development dynamics after 2008 are lowering slowly. In the case of Hungary (HU), the economic development path collapsed after 2008; then it began to move upward slowly, but it did not recover completely to the value from before the crisis. The last case is that of the Czech Republic, where growth dynamics recovered three years after the shock of the financial crisis, but dropped again after 2011 (see Figure 4).

The detailed analysis of the Central European regions' level of GDP and its growth dynamics puts broader light on the economic resilience processes taking place at the regional level. In general, there are only two regions with a polarised position in terms of maximisation of GDP and GDP growth dynamics. The first is Mazowieckie (PL12) which has the highest average value of GDP in the period of 2000-2014, but average GDP growth dynamics. The second is Bucuresti - Ilfov (RO32), which recorded the highest GDP growth dynamics, but with an average GDP level (see Figure 5).

For other Central European regions, there are several groups in terms of GDP level and GDP growth dynamics influencing their economic resilience. One includes regions with a relatively small average value of GDP but quite a high GDP growth dynamic. For example: (BG41) Yugozapaden, (RO11) Nord-Vest, (RO12) Centru, (RO21) Nord-Est, (RO22) Sud-Est, (RO31) Sud - Muntenia, (RO41) Sud-Vest Oltenia, (SK01) Bratislavský kraj, (SK02) Západné Slovensko, (SK03) Stredné Slovensko, and (SK04) Východné Slovensko. The economic resilience of these areas can be perceived as high. The other group consists of regions with a relatively good average value of GDP along with a relatively good level of GDP growth dynamics: (HU10) Közép-Magyarország, (PL22) Slaskie, (CZ01) Praha, (PL41) Wielkopolskie, (PL51) Dolnośląskie, and (PL21) Małopolskie. Thus, their economic resilience can be assessed as moderate. The rest of the regions form a mosaic of mixed low or medium sized average values of GDP and relatively low levels of GDP growth, which makes them low in economic resilience (see Figure 5).

Regional Statistics, Vol. 7. No.1. 2017: 043-062; DOI: 10.15196/RS07103 
Economic portfolio no. 1: the scale and dynamics of GDP

Figure 5 in CE regions (2000-2014) - standardised values

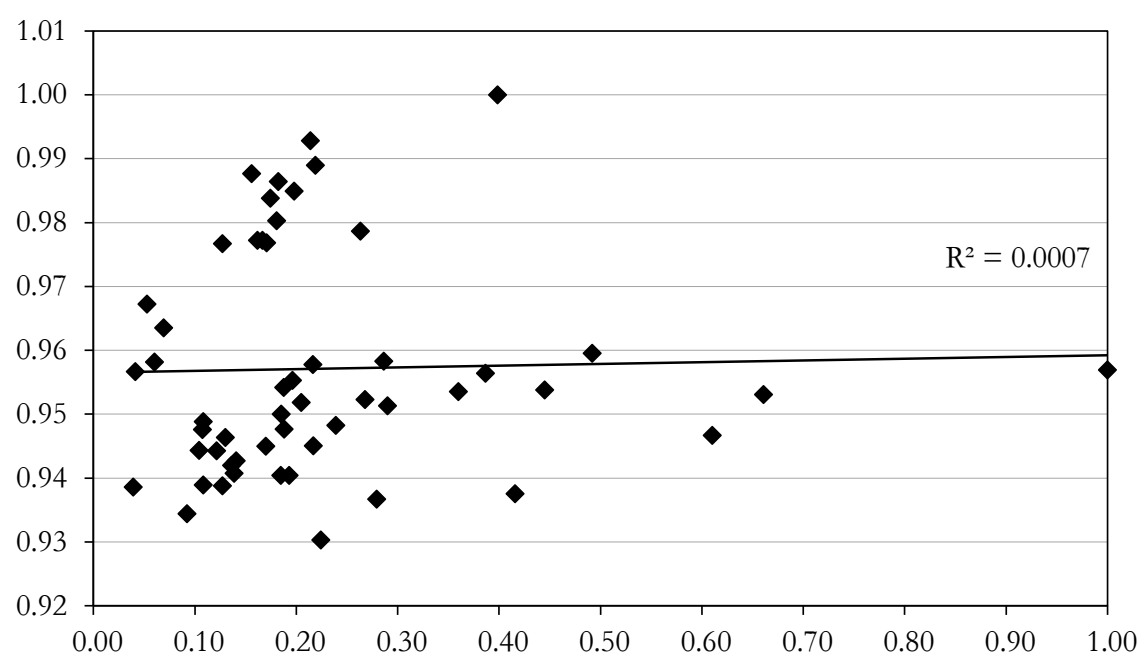

Source: calculation based on EUROSTAT.

Accounting for the impact of GDP changes expressed by the force of GDP changes along with the 'stability - instability' of GDP growth dynamics (measured by the coefficient of GDP variation) the pictures of economic resilience slightly differ from the one described in terms of GDP average value and GDP average dynamics. There are two polarised regions that have the highest force of GDP change (i.e. PL12: Mazowieckie) and the highest changeability (i.e. RO32: Bucuresti - Ilfov). There is also a group of regions with relatively high GDP growth changeability but very low impact of force of GDP changes (i.e. BG41: Yugozapaden, RO11: Nord-Vest, RO12: Centru, RO21: Nord-Est, RO22: Sud-Est, RO31: Sud - Muntenia, RO41: Sud-Vest Oltenia, RO42: Vest, SK01: Bratislavský kraj, SK02: Západné Slovensko, SK03: Stredné Slovensko, and SK04: Východné Slovensko (see Figure 6).

As in the previous analysis, there is a group of regions with a relatively high force of GDP change, but with medium or even low changeability of GDP change. This group includes (HU10) Közép-Magyarország, (PL22) Slaskie, (PL41) Wielkopolskie, (CZ01) Praha, (PL51) Dolnośląskie, and (PL21) Małopolskie.

The approach that applies the force of GDP changes and GDP changeability allows one to clearly distinguish the group of regions that have medium sized changeability of GDP but a very low level of force of GDP change. The core of this group is comprised of PL34: Podlskie, PL43: Lubuskie, PL52: Opolskie, PL33: Świętokrzyskie, and BG32: Severen tsentralen. All other Central European regions can be classified as economically vulnerable (i.e. as having a small force of GDP

Regional Statistics, Vol. 7. No.1. 2017: 043-062; DOI: 10.15196/RS07103 
change and small changeability of GDP dynamics). Examples include BG31: Severozapaden, HU10: Közép-Magyarország, HU31: Észak-Magyarország, HU32: Észak-Alföld, HU33: Dél-Alföld, and SI01: Vzhodna Slovenija (Figure 6).

Figure 6

Economic portfolio no 2: the changeability and force of changes of GDP in EU countries (2000-2014) - standardized values

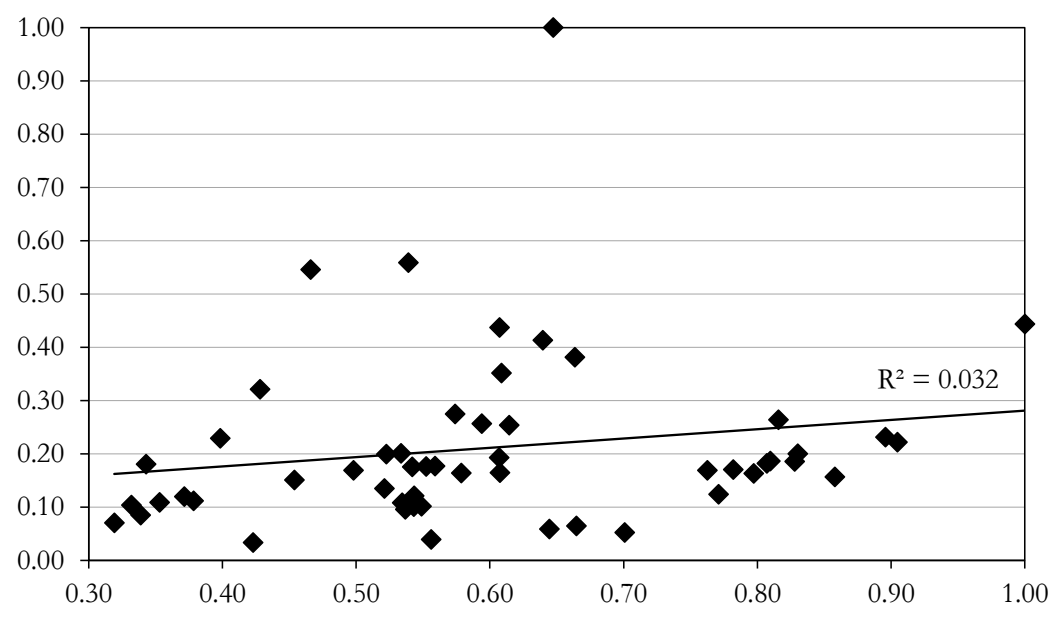

Source: calculation based on EUROSTAT.

Let us look at the GDP dynamics indicators with a baseline index for the 10 best regions of Central Europe. Within the period of 2000-2014 all of them registered excessive growth of GDP (i.e. their GDP tripled at least). Over four times growth was registered for RO32: Bucuresti - Ilfov, and four times growth of GDP for BG41: Yugozapaden. As shown in Figure 7, almost all analysed regions were impacted by the global financial crisis, which made their path of growth collapse after 2008. Their strong economic resilience, however, has allowed them to bounce back to their previous paths of growth. The region most stricken by the crisis had the highest GDP growth dynamics (i.e. RO32: Bucuresti - Ilfov), but its economy recovered in four years. The most shock-resistant was SK01: Bratislavský kraj, which did not break its growth dynamics after 2008 (see Figure 7).

A completely different level of economic resilience applies to the 10 regions with the poorest performance of GDP dynamics in Central Europe. Almost none of them recovered after the global financial crisis. The exceptions are BG31: Severozapaden and PL42: Zachodniopomorskie, in which the path of GDP growth dynamics fully recovered after the global financial crisis (see Figure 8). The other regions' development paths collapsed after 2008. In some of the regions, GDP growth dynamics have displayed a horizontal trend of stagnation (i.e. HR03: Jadranska Hrvatska, HR04: Kontinentalna Hrvatska, HU23: Dél-Dunántúl, SI01:

Regional Statistics, Vol. 7. No.1. 2017: 043-062; DOI: 10.15196/RS07103 
Vzhodna Slovenija). Another group has not yet recovered (i.e. HU21: KözépDunántúl, HU31: Észak-Magyarország, HU32: Észak-Alföld, and SI02: Zahodna Slovenija; see Figure 8).

Dynamics of GDP in 10 Central European regions (NUTS2) with the best performance in the years 2000-2014 $(2000=100)$

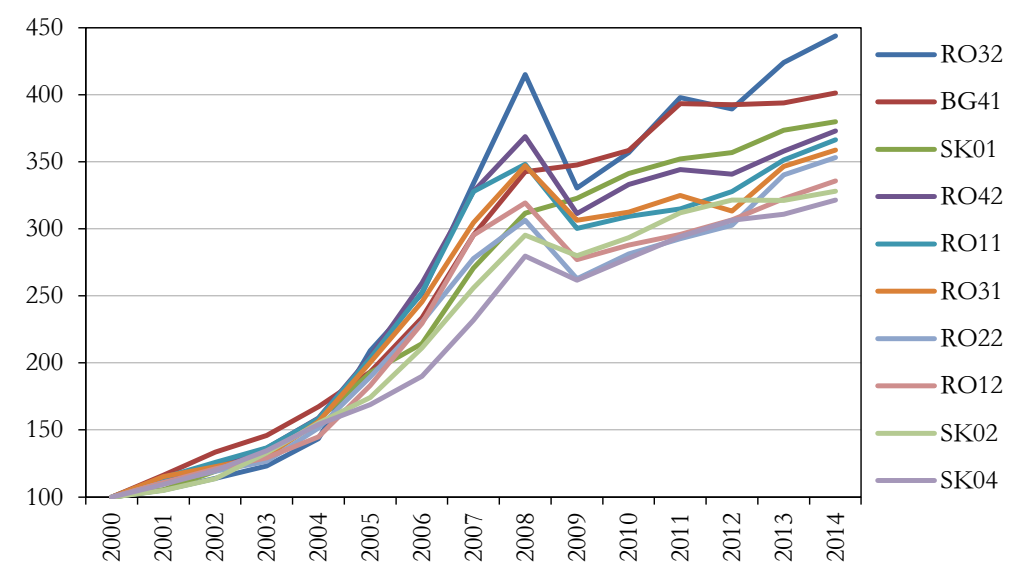

Source: calculation based on EUROSTAT.

Abbreviations: (BG41) Yugozapaden, (RO32) Bucuresti - Ilfov, (RO11) Nord-Vest, (RO12) Centru, (RO22) Nord-Est, (RO31) Sud - Muntenia, (RO42) Vest, (SK01) Bratislavský kraj, (SK02) Západné Slovensko, and (SK04) Východné Slovensko.

Dynamics of GDP in 10 Central European regions (NUTS2)

Figure 8 with the poorest performance in the years 2000-2014 $(2000=100)$

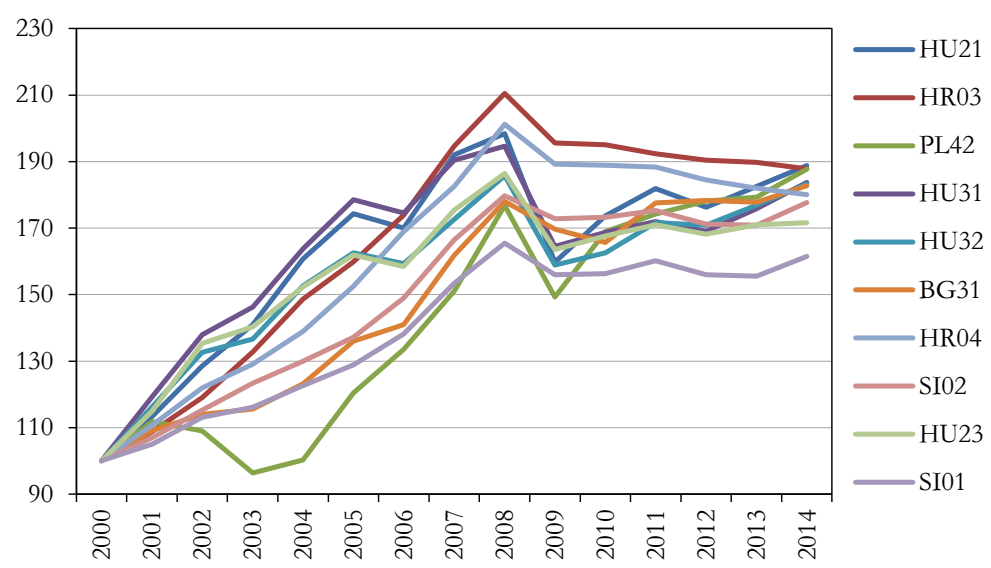

Source: calculation based on EUROSTAT

Abbreviations: (BG31) Severozapaden, (HR03) Jadranska Hrvatska, (HR04) Kontinentalna Hrvatska, (HU21) Közép-Dunántúl, (HU23) Dél-Dunántúl, (HU31) Észak-Magyarország, (HU32) Észak-Alföld, (PL42) Zachodniopomorskie) (SI01) Vzhodna Slovenija, and (SI02) Zahodna Slovenija.

Regional Statistics, Vol. 7. No.1. 2017: 043-062; DOI: 10.15196/RS07103 


\section{Discussion and conclusions: from resilience to hybridization of development}

This study of the initial identification of resilience at both national and regional levels, with particular attention to the Central European regions, provides some general conclusions. The first concerns the clear variation in the level of resilience among the surveyed territorial units. The second, associated with the first, involves the possibility of identifying several strategic groups among territorial units in relation to the phenomenon of resilience. The third, more general, refers to the hybridization of development which is the consequence of seeking and building an adaptive capacity in the analysed territorial units.

A very high level of variation in resilience is evident mainly in the following portfolios: GDP growth and dynamics and GDP changeability and force of GDP change at both the EU and the Central Europe levels. It is also confirmed by the classical GDP growth indicators (fixed baseline indicators). Among the analysed countries of the EU, they show very large imbalances between their scale of economies (measured by GDP) and corresponding growth patterns (measured by GDP average growth dynamics) in the years 2000 to 2014. In general, the socalled 'old' EU countries, despite their economies' scale, show a lower GDP growth rate (ranging from 124 to 211 GDP value for the year 2000). In the Central European countries the value of growth varies between 170 and 368 GDP values in the year 2000 .

In principle, all the EU countries experienced a collapse of GDP growth as a result of the global financial crisis. Some were highly resistant to this economic shock, maintaining their growth rates (i.e. Malta and Bulgaria). Some undertook adjustment processes to recover their growth dynamics (i.e. Austria, Belgium, Denmark, Finland, France, the Netherlands, Ireland, Luxembourg, Germany, Poland, Romania, Slovakia, Sweden, and the United Kingdom). These adjustments, however, took different times (i.e. from two to seven years). The rest of the countries have not recovered their growth dynamics and have fallen into recession or stagnation (i.e. Cyprus, the Czech Republic, Greece, Spain, Croatia, Malta, Portugal, Slovenia, Hungary, and Italy). Even higher levels of GDP growth dynamics variation apply to the Central European regions. The value of growth dynamics ranges from 161 to 444 of the GDP value for the year 2000. Even regions with the highest dynamics of growth have been affected by the global financial crisis of 2008 (the exceptions are BG41: Yugozapaden and SK01: Bratislavský kraj). However, the recovery period has not taken more than two to three years.

The study conducted allows one to identify a few strategic groups, both among the EU countries and the regions of Central Europe, regarding the economic resilience phenomenon, ordered by the scale of GDP (or force of GDP change) and the dynamics of GDP growth (or changeability of GDP). The countries at opposite extremes are those which have a large-scale economy and low growth dynamics,

Regional Statistics, Vol. 7. No.1. 2017: 043-062; DOI: 10.15196/RS07103 
called giant\&slow (i.e. Germany, United Kingdom, France, and Italy), and those with small scale economies and high dynamics of growth, called small\&fast (i.e. Romania, Slovakia, Estonia, Bulgaria, Lithuania, and Latvia). Interestingly, both groups are characterised by a high level of economic resilience.

Other EU countries have a very diverse position in terms of size and dynamics of economy, and thus resilience. The group of countires with medium-sized economies and average dynamics of GDP growth, called medium\&medium, includes the Czech Republic and Poland. The group with medium-sized economies and low GDP growth rates is called medium\&slow and includes Austria, Spain, Holland, Belgium, Sweden, Hungary, Denmark, Finland, and Ireland. Both 'medium' groups are resilient, albeit to varying degrees. The last group includes countries with small economies and small GDP growth, called small\&slow (i.e. Croatia, Malta, Luxembourg, Cyprus, Greece, and Slovenia). In their case, the level of resilience is very low.

Nearly identical strategic groups can be identified in the Central European regions, in terms of economic size and dynamics of growth. The giant-medium group consists of only one region (i.e. PL12: Mazowieckie). Similarly, the medium-fast group includes only RO32: Bucuresti - Ilfov. There is a large group of small-fast regions, bringing together regions from Romania and Slovakia. The mediummedium group comprises mainly the metropolitan regions of Budapest, Prague, and the most economically strong regions of Poland (Slaskie, Wielkopolskie, Dolnośląskie and Małopolskie). All the indicated groups are characterised by satisfactory resilience. The small-medium group includes, among other things, small Polish and Bulgarian regions with average GDP growth dynamics (e.g. Lubuskie, Opolskie, Swietokrzyskie, Podkaprackie, and Severen tsentralen). The small-slow group, on the other hand, refers mainly to economically small, in absolute terms, Hungarian and Slovenian regions that are de facto characterised by low resilience.

In general, among the Central European regions, a large number of regions have GDP growth defined as 'medium' or 'slow'. This could mean the emergence of the 'middle income trap' problem in their case. The sources of this problem can be found in the specific conditions of their development (i.e. in the post-socialism legacy that makes it difficult to build adaptability towards changes in the global economy).

Other groups (i.e. 'medium-fast' and 'small-fast'), comprise regions with high growth dynamics. Such regions are likely to 'move to a different domain' in a relatively quick way, even after the shock of the global financial crisis. They have apparently invented a new configuration or development path during the surveyed period. Thus, in their case negative hysteresis or the 'remanence' effect (Martin 2012) have not occurred. This means that one-time disturbances (like the mentioned financial crisis) did not permanently affect the development of their economies in a serious way. There remains a question, however, of whether these high rates of GDP

Regional Statistics, Vol. 7. No.1. 2017: 043-062; DOI: 10.15196/RS07103 
growth will be sustained in the long run as a consequence of a new path of development connected with the region's entry into global production chains. However, this requires more detailed research into changes in the economic structure of these regions.

This kind of mosaic of economic behaviour towards tendencies and economic changes (like the good economic situation existing until 2008, the global financial crisis) indicates the development of very diverse paths of growth in the territorial dimension. In this way, building the capacity of regional resilience (and consequently resilience at the country level) leads to a lack of one-way relationships between the size of the economy and the dynamics of its development (this is also confirmed by the low value of $\mathrm{R} 2$ indicators for regional analysis), as shown in the above analyses. Such a lack of dependence can be expressed in the context of the hybridization of growth patterns.

The notion of hybridization is present in, among other things, considerations of globalisation, meaning, in the economic sense, the increase of international trade in goods, technology, people, and ideas resulting in a variety of effects. In the territorial dimension, the high level of economic diversification is the basis for Golubchikov to define the assumptions of such hybridization. It explains the different dynamics of the territorial units development based on mutual interactions between the postsocialist legacy and the forces of neoliberal capitalism (Golubchikov et al. 2014, Sýkora-Bouzarovsky 2012). These relationships have a direct impact on the results of the analysis carried out for the Central European regions.

In the territorial dimension, hybrid development is a type of uneven development resulting from the influence of neo-liberal capitalism, for which, in terms of effective capital allocation, only those places are important which provide a satisfactory return on investments. Hybridization of development is simultaneously a result of a post-socialist legacy that has determined a specific accumulation of capital, expressed in the location of a particular type of social and technical infrastructure, economic activity, and human and social capital. In the regional dimension, the post-socialist legacy is perceived by Golubchikov according to the concept of pathdependence and lock-in. Such elements consequently determine the resilience attributes, generating a multidimensional picture of economic effects as a response to changes in the surroundings.

Summing up, the hybridization of regions' development is a consequence of the creation of diverse solutions for enhancing the attributes of economic resilience. As Cooke notes, one strategy for a region's adaptation to changes is to develop a system of economic structures that can create or attract new technologies along with new products that can be quickly sold. This kind of structure requires that regions combine rapidly different resources to obtain new, functionally enhanced products (functional diversity), including greater flexible modification. Thus, the process of building economic resilience of regions is conducive to the emergence of multifac-

Regional Statistics, Vol. 7. No.1. 2017: 043-062; DOI: 10.15196/RS07103 
eted effects of different scales and different nonlinear ranges, resulting in a variety of growth dynamics recorded in the spatial dimension.

\section{REFERENCES}

Barnett, J. (2001): Adapting to Climate Change in Pacific Island Communities World Development 29 (6): 977-993.

BERKES, F. et al. (2003): Navigating social-ecological systems. Building resilience for complexity and change Cambridge University Press, Cambridge.

BOSHER, L.-COAFFEE, N. (2008): Editorial: International Perspective on Urban Resilience Urban Design and Planning 161 (4): 145-146.

Briguglio, L.-CordinA, G.-BugejA, S. et al. (2006): Conceptualizing and Measuring Economic Resilience University of Malta, Department of Economics, Mimeo.

Briguglio, L.-Cordina, G.-Farrugia, N.-Velda, S. (2008): Economic Vulnerability and Resilience: Concepts and Measurements. Research Paper No. 55, United Nation University, Geneva.

COOKE, PH. (2008): Regional innovation systems, clean technology and Jacobian clusterplatform policies Regional Sciences, Policy and Practice 1 (1): 23-45.

Desmet, K.-Rossi-Hansberg, E. (2009): Spatial Growth and Industry Age Journal of Economics Theory 144: 2477-2502.

DrobNiAK, A. (2014): Method for assessing the resilience of city In: DrobNIAK, A. (ed.): Urban resilience concept and post-industrial cities in Europe pp. 49-74., University of Economics in Katowice - HELION SA Publishing Group, KatowiceGliwice.

DrobniaK, A. (2012): The urban resilience - economic perspective Journal of Economics and Management 10: 5-20.

ERAYDIN, A. (2016): Attributes and characteristics of Regional Resilience: Defining and Measuring the Resilience of Turkish Regions Regional Studies 30 (4): 600-614.

ERAYDIN, A.-TAŞAN-KoK, T. (2013): Introduction: Resilience Thinking in Urban Planning In ERAydin, A.-TAşAn-KoK, T. (eds.): Resilience Thinking in Urban Planning pp. 1-16., Springer, Dordrecht.

Foster, K. A. (2007): A Case Study Approach to Understanding Regional Resilience Working Paper 2007-08. Institute of Urban and Regional Development, University of California, Berkeley.

GERST, J.-DOMS, M.-DALY, M. C. (2009): Regional Growth and Resilience: Evidence from Urban IT Centers. FRBSF Economic Review: 1-11.

Gleaser, E. L.-SAIZ, A. (2004): The Rise of the Skilled City In: GALE, W.G. - RotheNBERG, P. J. (eds.) Brookings Wharton Paper on Urban Affairs: 47-94.

Godschalk, D. R. (2003): Urban hazard mitigation: Creating resilient cities Natural Hazards Review 4 (3): 136-143.

Golubchikov, O.-BAdyinA, A.-MAKHrova, A. (2014): The Hybrid Spatialities of Transition: Capitalism, Legacy and Uneven Urban Economic Restructuring Urban Studies 51 (4): 617-633.

HESS, D. (2013): Sustainable consumption, energy and failed transitions: the problem of adaptation In: Cohen, M. J.-SZEjnwald Brown, H.-Vergragt, P. J. (eds.):

Regional Statistics, Vol. 7. No.1. 2017: 043-062; DOI: 10.15196/RS07103 
Innovations in Sustainable Consumption. New Economies, Socio-technical Transitions and Social Practices pp. 159-178., Edward Elgar Publishing, Cheltenham.

HiLl, E.-Clair, T.-WiAl, H. et al. (2010): Economic Shocks and Regional Economic Resilience Conference on Urban and Regional Policy and its Effects: Building Resilience Regions, May 20-21., George Washington, Urban Institute, Washington, D.C.

Hoolling, C. S. (2001): Understanding the Complexity of Economic, Ecological and Social Systems Ecosystems 4 (5): 390-405.

Hudson, R. (2010): Resilient regions in an uncertain world: wishful thinking or a practical reality? Cambridge Journal of Regions, Economy and Society 3 (1): 11-25.

KLEIN, R. J. T. et al. (2003): Resilience to natural hazards. How useful is the concept? Environmental Hazards 5 (1-2): 35-45.

LANG, T. (2011): Urban Resilience and New Institutional Theory - A Happy Couple for Urban and Regional Studies? German Annual of Spatial Research and Policy 2010., Berlin - Heidelberg.

Lansford, T.-Covarrubias, J.-CARriere, B.-Miller, J. (2010), Fostering Community Resilience. Homeland security and hurrican Katrina Ashgate, Farnham.

MARTIN, R. (2012): Regional economic resilience, hysteresis and recessionary shocks Journal of Economic Geography 12 (1): 1-32.

Nunn, N. (2009): The Importance of History for Economic Development NBER Working Paper 14899. National Bureau of Economic Research, Cambridge, MA.

PATKAR, M., R.-KESKAR, Y. M. (2014): Hibridization as a New Paradigm of Urban Development in metropolitan city, case of Pune City, India International Journal of Innovative Research in Science Engineering and Technology 3 (1): 8529-8536.

SiMmE, J.-MARTIN, R. (2010): The economic resilience of regions: towards an evolutionary approach Cambridge Journal of Regions, Economy and Society 3 (1): 27-43.

SÝKORA, L.-BOUZAROVSKY, S. (2012): Multiple transformations: Conteptualising the Postcommunist Urban Transition Urban Studies 49 (1): 43-60.

TAŞAN-KOK, T.-DOMINIK, S.-LU, P. (2013): Conceptual Overview of Resilience: History and Context In: Eraydin, A.-TAŞAN-KoK, T. (eds.): Resilience Thinking in Urban Planning pp. 39-51., Springer Dordrecht.

WALKER, B.-SALT, D. (2006), Resilience thinking: Sustaining ecosystems and people changing world Island Press, Washington.

WARDEKKER, J. A. et al. (2010): Operationalising the resilience approach to adapting an urban delta to uncertain climate changes Technological forecasting and Social Change 77 (6): 987-998.

Welter-EnderLIN, R. (2006): Resilienz - Gedeihen trotz widriger Umstände Carl-AuerSysteme, Heidelberg.

Regional Statistics, Vol. 7. No.1. 2017: 043-062; DOI: 10.15196/RS07103 